\title{
Contribution of Diffusion-Weighted Imaging to Diagnosis and Staging of Cervical Cancer
}

\author{
Tuna Demirbaş ${ }^{1}$, Tan Cimilli², Sibel Bayramoğlư ${ }^{2}$, Nurten Turan Güner ${ }^{2}$, Elif Hocaoğlu ${ }^{2}$, Ercan İnci ${ }^{2}$ \\ ${ }^{1}$ Department of Radiology, Çarsamba District Hospital, Samsun, Turkey \\ ${ }^{2}$ Department of Radiology, Bakirkoy Training and Research Hospital, İstanbul, Turkey
}

Background: Cervical cancer is the second most common female malignancy worldwide. Although its incidence has decreased in developed countries due to screening with Papanicolaou test, it is still the leading cause of cancer-related female death in developing countries.

Aims: The aim of this study was to determine whether the apparent diffusion coefficient (ADC) measurements calculated from diffusionweighted imaging (DWI) images had any contribution in differentiation of normal cervical tissue from malignant lesions preoperatively, and whether there was a correlation between the mean ADC values and tumor type, grade, or stage in malignant lesions.

Study Design: Case-control study.

Methods: Mean ADC values in 25 patients who had cervical cancer proved histopathologically, and 20 patients with otherwise normal uterus were compared. Also in the study group, mean ADC values were compared between histopathologic subtypes, tumor grades, and stages.
Results: In the study group the mean ADC values $(0.96 \pm 0.15 \times 10$ $3 \mathrm{~mm}^{2} / \mathrm{s}$ ) were statistically lower than that of the control group $\left(1.67 \pm 0.17 \times 10^{-3} \mathrm{~mm}^{2} / \mathrm{s}\right)(\mathrm{p}<0.05)$. According to histopathologic subtypes there was no significant difference between mean ADC values of squamous cell cancer and adenocarcinoma $\left(0.95 \times 10^{-3} \mathrm{~mm}^{2} / \mathrm{s}\right.$ and $0.91 \times 10^{-3} \mathrm{~mm}^{2} / \mathrm{s}$, respectively) $(\mathrm{p}>0.05)$. There was also no significant difference between the mean ADC values of the tumor grades $(\mathrm{p}>0.05)$. The mean ADC values in early stage cervical cancer $\left(0.86 \pm 0.05 \times 10^{-3} \mathrm{~mm}^{2} / \mathrm{s}\right)$ were significantly lower than the mean ADC values in late stage disease $\left(0.98 \pm 0.06 \times 10^{-3} \mathrm{~mm}^{2} / \mathrm{s}\right)(\mathrm{p}<0.05)$.

Conclusion: ADC value measurements may provide useful information in diagnosis of cervical cancer as well as in preoperative assessment of the tumor stage.

(Balkan Med J 2014;31:154-7).

Key Words: Apparent diffusion coefficient, cervical cancer, cervix, magnetic resonance
Cervical cancer is a common gynaecological malignancy worldwide. Although it can be prevented by using the recently found vaccine against the human papilloma virus (HPV) and its incidence has decreased in developed countries due to screening with the Papanicolaou test (Pap smear), cervical cancer is still a prominent cause of malignancy-related death (1-3). Among the imaging modalities used in the preoperative evaluation of cervical cancer, magnetic resonance imaging (MRI) is excellent for demonstrating the internal anatomy. Diffusion weighted imaging (DWI) is a recent approach for evaluating malignancies. Although it is widely used in the detection and evaluation of acute stroke $(4,5)$, with improving MRI technology that has reduced the artefacts interfering with the image interpretation, DWI has been used in body imaging $(6,7)$. Apparent diffusion coefficent (ADC) maps are calculated from DWI images and it has been reported that quantitative evaluation of ADC values might be used for differentiating benign from malignant tissue (8). In the present study the aim was to identify whether the ADC measurements made any contribution to the differentiation of normal cervical tissue and malignant lesions preoperatively, and whether in malignant lesions there was a correlation between the mean ADC values and tumour type, grade or stage.

\section{MATERIAL AND METHODS}

Patients who had cervical cancer proved histopathologically between June 2009 and June 2011 were taken as the study group but rare cervical cancer subtypes like small-cell carcinoma were excluded from the study because of insufficient numbers. The magnetic resonance (MR) data of 25 patients was taken into account consisting of 21 squamous cell cancers and four adenocarcinomas. Twenty patients with an otherwise normal uterus who underwent MRI because of adnexal pathologies constituted the control group. The MR data, obtained via a 1.5-T MR scanner (Avanto; Siemens, Erlangen, Germany) with eight-channel body coil, was evaluated retrospectively. MRI protocol for pelvic imaging consists of these sequences with corresponding parameters: axial turbo-spin-echo T1-weighted im- 
ages (T1WI) with a repetition time (TR) of $536 \mathrm{~ms}$ and echo time (TE) of $11 \mathrm{~ms}$; axial turbo-spin-echo T2WI with a TR of $4320 \mathrm{~ms}$ and TE of $87 \mathrm{~ms}$; sagittal turbo-spin-echo T2WI with a TR of 5030 $\mathrm{ms}$ and TE of $101 \mathrm{~ms}$; coronal turbo-spin-echo turbo inversion recovery magnitude (TRIM) sequence with a TR of $4980 \mathrm{~ms}$ and TE of $84 \mathrm{~ms}$; and an axial DW spin-echo echo-planar sequence with a TR of $4900 \mathrm{~ms}$ and TE of $93 \mathrm{~ms}$ with $b$ factors of 0,500 and $1000 \mathrm{~s} /$ $\mathrm{mm}^{2}$. After that, contrast-enhanced axial and sagittal spin-echo T1WI with fat suppression were acquired using $0.1 \mathrm{mmoL} / \mathrm{kg}$ gadopentate dimeglumine (Magnevist; Bayer Schering Pharma AG; Berlin, Germany) administered intravenously. ADC maps were calculated from DW images that were previously assessed by an experienced radiologist for image quality. In the patient group, ADC measurements were executed on reconstructed ADC maps with the largest region of interest (ROI) within the tumour. ROIs were set up three times and the average of them was used for each ADC value measurement. In the control group, $\mathrm{ADC}$ measurements of the normal cervical tissue were taken by setting the ROIs excluding the stroma to avoid mismeasurement arising from short T2WI values (9). A $t$-test was used to analyse comparisons and a palue $<0.05$ was accepted as statistically different. Mean ADC values in the patient group and control group were compared. Also, in the study group, comparisons of mean ADC values between histopathological subtypes, tumour grades and stages were made. This study was approved by the Bakirköy Training and Research Hospital Ethics Committee (decision no: 2014/04).

\section{RESULTS}

The average age of the patient group (aged between 52 and 74) was $60.7 \pm 7.6$ years and that of the control group (aged between 47 and 72) was $58.6 \pm 8.1$ years. No significant statistical difference was found between the average ages ( $p>0.05)$.

The mean ADC value of the study group was $0.96 \pm 0.15 \times 10^{-3} \mathrm{~mm}^{2} / \mathrm{s}$ and in the control group the mean ADC value was $1.67 \pm 0.17 \times 10^{-3} \mathrm{~mm}^{2} / \mathrm{s}$. In the study group, the mean $\mathrm{ADC}$ values were statistically lower than those of the control group $(p<0.05)$ (Figure 1). There were 21 patients with squamous cell cancer and four patients with adenocarcinoma with mean $\mathrm{ADC}$ values of $0.95 \times 10^{-3} \mathrm{~mm}^{2} / \mathrm{s}$ and $0.91 \times 10^{-3} \mathrm{~mm}^{2} / \mathrm{s}$, respectively. Although mean ADC values of the adenocarcinoma group were lower than those of the squamous cell cancer group, because of the difference between the number of patients, statistical analysis could not be performed (Table 1). With regards to tumour grades, no statistical difference was found between the mean ADC values (grade I n:13, grade II n:7 and grade III n:5 with mean ADC values of $0.95 \times 10^{-3} \mathrm{~mm}^{2} / \mathrm{s}, 0.94 \times 10^{-3} \mathrm{~mm}^{2} / \mathrm{s}$ and $0.97 \times 10^{-3} \mathrm{~mm}^{2} / \mathrm{s}$, respectively; $\mathrm{p}>0.05$ ) (Table 1 ).

According to the International Federation of Gynaecology and Obstetrics (FIGO), classification stages I--IIa are considered early stage and stages IIb or more are considered late stage (10). Eleven patients were in the early stage with $10 \mathrm{pa}-$ tients in stage $\mathrm{Ib}$ and one in stage IIa, whereas 14 patients were in the late stage with three patients in stage IIb, two patients
TABLE 1. Comparison of ADC values between the histopathologic subtypes, tumor stage and tumor grades

\begin{tabular}{lcc}
\hline \multicolumn{2}{c}{ Number of patients (n) } & Mean ADC value \\
\hline Histopathology & & \\
$\quad$ Squamous cell cancer & 21 & $0.95 \times 10^{-3} \mathrm{~mm}^{2} / \mathrm{s}$ \\
$\quad$ Adenocarcinoma & 4 & $0.91 \times 10^{-3} \mathrm{~mm}^{2} / \mathrm{s}$ \\
Tumor stage & & \\
Early stage (stages I-IIa) & 11 & $0.86 \times 10^{-3} \mathrm{~mm}^{2} / \mathrm{s}$ \\
Late stage (stages IIb-IV) & 10 & $0.98 \times 10^{-3} \mathrm{~mm}^{2} / \mathrm{s}$ \\
Tumor grade & & \\
Grade I & 13 & $0.95 \times 10^{-3} \mathrm{~mm}^{2} / \mathrm{s}$ \\
Grade II & 7 & $0.94 \times 10^{-3} \mathrm{~mm}^{2} / \mathrm{s}$ \\
Grade III & 5 & $0.97 \times 10^{-3} \mathrm{~mm}^{2} / \mathrm{s}$ \\
\hline
\end{tabular}

ADC: apparent diffusion coefficient

Mean ADC values were significantly lower in early stage disease ( $p<0.05$ ). No significant difference was found between the mean $\mathrm{ADC}$ values of histopathologic subtypes and tumor grades $(\mathrm{p}>0.05)$

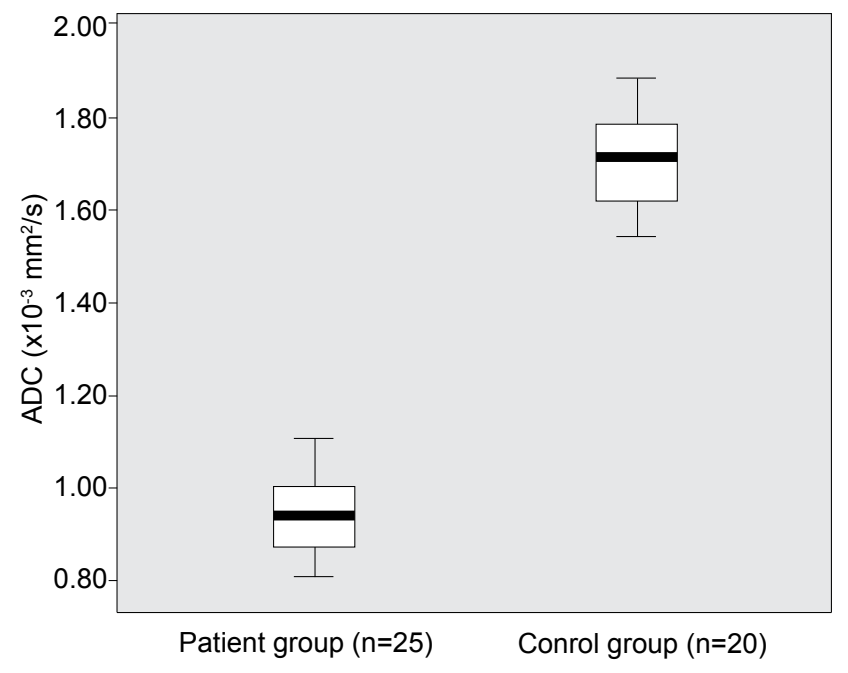

FIG. 1. Comparison of the mean ADC values between patient group and control group. Cervical cancer was found to have significantly lower mean ADC values than normal cervical tissue $(p<0.05)$.

in stage IIIa, four patients in stage IIIb, four patients in stage IVa and one patient in stage IVb. The mean ADC values in early-stage cervical cancer $\left(0.86 \pm 0.05 \times 10^{-3} \mathrm{~mm}^{2} / \mathrm{s}\right)$ were significantly lower than the mean $\mathrm{ADC}$ values in the late stage of the disease $\left(0.98 \pm 0.06 \times 10^{-3} \mathrm{~mm}^{2} / \mathrm{s}\right)(\mathrm{p}<0.05)$. A comparison of mean ADC values between early- and late-stage disease is shown in Table 1 and Figure 2.

\section{DISCUSSION}

Magnetic Resonance Imaging with high soft-tissue resolution is the most valuable imaging modality in the assessment 


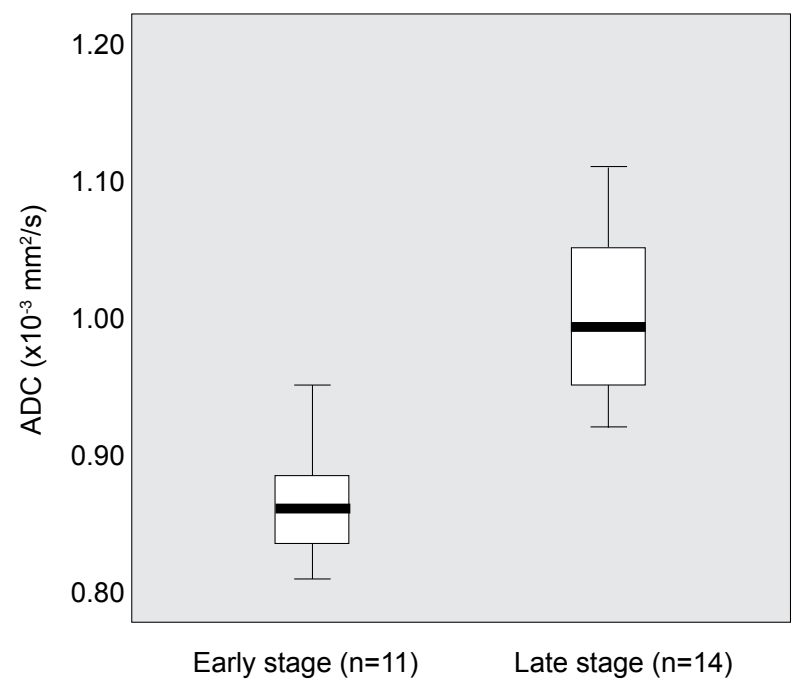

FIG. 2. Comparison of mean ADC values for early and late stage cervical cancer according to FIGO classification. There was a significant difference between early and late stage cervical cancer $(p<0.05)$.

of tumour size, depth of cervical invasion and extent of locoregional spread in the treatment planning of cervical cancer $(11,12)$. DWI, which has recently been used in the diagnosis of malignant lesions, can distinguish the normal uterine cervix from cervical cancer and benign lymph nodes from malignant ones (13). In the study of Naganawa et al. (14), mean ADC values were found to be significantly lower in cervical cancer than in the control group. Despite the small study population, this study has shown that ADC measurement has a potential value for distinguishing normal cervical tissue from cancerous cervical tissue. With a larger study population, McVeigh et al. (8) reported that mean $\mathrm{ADC}$ values of patients with cervical cancer were lower than normal cervix ADC values. Also, with regard to FIGO classification, mean ADC values were found to be lower in stages Ib/IIa than in stage IIb and stages III/IV, as is found in this study. The significant difference between the FIGO stages may be a useful factor in treatment planning, especially for cases in which the extent of the disease is undetermined. In a recent study by Kuang et al. (15), it was concluded that in the evaluation of cervical cancer, the diagnostic accuracy of ADC values for the distinction of cancerous from normal tissue was high. A similar study by Zhang et al. (16) reported lower mean $\mathrm{ADC}$ values for cervical cancer than for a normal cervix. Also, it is reported that there was an increase in ADC values after radiotherapy, which indicated that DWI might be used to monitor the response to therapy. Similarly, Makino et al. (17) observed that in patients with cervical cancer, the measurement of ADC values could be an important factor for assessing response to chemoradiotherapy. In another study by Kilickesmez et al. (18), it was shown that mean
ADC values could be used for distinguishing benign uterine pathologies from malignant uterine pathologies. Liu et al. (19) stated that mean ADC values were lower in cervical cancer than in normal uterine tissue. A negative correlation between tumour grade and mean ADC values and lower mean ADC values for squamous cell carcinoma than for adenocarcinoma were also reported. In the present study, there was no significant statistical difference between mean ADC values with regard to tumour grade. This inconsistency may be related to the smaller patient group of our study. One of the limitations of our study was that it did not encompass all of the cervical cancer subtypes. In the histopathological subgroup, the number of patients with adenocarcinoma was lower than the number of patients with squamous cell carcinoma and this interfered with carrying out a statistical analysis. Besides the preoperative uses, there are a number of studies on the postoperative use of mean ADC values. According to Nakamura et al. (20), preoperative mean $\mathrm{ADC}$ values might also be used as a predictive factor for relapse of cervical cancer.

Although there are no similar studies with larger populations on the use of ADC measurements in cervical cancer, existing studies along with this study indicate that $A D C$ value measurements may provide convenient data for the diagnosis of cervical cancer as well as for preoperative assessment of the tumour stage.

Ethics Committee Approval: Ethics committee approval was received for this study from Bakırköy Training and Research Hospital Ethics Committee (decision no: 2014/04).

\section{Informed Consent: N/A.}

Peer-review: Externally peer-reviewed.

Author contributions: Concept - T.D., T.C., S.B.; Design - T.D., T.C., N.T.G.; Supervision - T.C., S.B., E.H.; Resource - T.C., S.B., E.H.; Materials - T.D., T.C., N.T.G.; Data Collection\&/or Processing - T.D., S.B., E.I.; Analysis\&/or Interpretation - T.D., N.T.G., E.H.; Literature Search - T.D., N.T.G., E.H.; Writing - T.D., T.C., E.H.; Critical Reviews - T.C., S.B., E.İ.

Conflict of Interest: No conflict of interest was declared by the authors.

Financial Disclosure: The authors declared that this study has received no financial support.

\section{REFERENCES}

1. Walboomers JM, Jacobs MV, Manos MM, Bosch FX, Kummer JA, Shah KV, et al. Human papillomavirus is a necessary cause of invasive cervical cancer worldwide. J Pathol 1999;189:12-9. [CrossRef]

2. Solomon D, Breen N, McNeel T. Cervical cancer screening rates in the United States and the potential impact of implementation of screening guidelines. CA Cancer J Clin 2007;57:105-11. [CrossRef]

3. Schiffman MH, Bauer HM, Hoover RN. Epidemiologic evidence showing that human papillomavirus infection causes most cervical intraepithelial neoplasia. J Natl Cancer Inst 1993;85:958-64. [CrossRef] 
4. Le Bihan D, Breton E, Lallemand D, Grenier P, Cabanis E, Laval-Jeantet M. MR imaging of intravoxel incoherent motions: application to diffusion and perfusion in neurologic disorders. Radiology 1986;161:401-7.

5. Sorensen AG, Wu O, Copen WA. Human acute cerebral ischemia: detection of changes in water diffusion anisotropy by using MR imaging. Radiology 1999;212:785-92. [CrossRef]

6. Kurihara Y, Yakushiji YK, Tani I, Nakajima Y, Van Cauteren M. Coil sensitivity encoding in MR imaging: advantages and disadvantages in clinical practice. AJR Am J Roentgenology 2002; 178:1087-91. [CrossRef]

7. Takahara T, Imai Y, Yamashita T, Yasuda S, Nasu S, Cauteren M. Diffusion weighted whole body imaging with background body signal supression (DWIBS): technical improvement using free breathing, STIR and high resolution 3D display. Radiat Med 2004;22:275-82.

8. McVeigh PZ, Syed AM, Milosevic M, Fyles A, Haider MA. Diffusionweighted MRI in cervical cancer. Eur Radiol 2008;18:1058-64. [CrossRef]

9. Charles-Edwards EM, deSouza NM. Diffusion-weighted magnetic resonance imaging and its application to cancer. Cancer Imaging 2006;6:135-43. [CrossRef]

10. Pecorelli S, Zigliani L, Odicino F. Revised FIGO staging for carcinoma of the cervix. Int J Gynaecol Obstet 2009;105:107-8. [CrossRef]

11. Scheidler J, Heuck AF. Imaging of cancer of the cervix. Radiol Clin North Am 2002;40:577-90. [CrossRef]

12. Ascher SM, Takahama J, Jha RC. Staging of gynecologic malignancies. Top Magn Reson Imaging 2001;12:105-29. [CrossRef]
13. Chen YB, Hu CM, Chen GL, Hu D, Liao J. Staging of uterine cervical carcinoma: whole-body diffusion-weighted magnetic resonance imaging. Abdom Imaging 2011;36:619-26. [CrossRef]

14. Naganawa S, Sato C, Kumada H, Ishigaki T, Miura S, Takizawa O. Apparent diffusion coefficient in cervical cancer of the uterus: comparison with the normal uterine cervix. Eur Radiol 2005;15:71-8. [CrossRef]

15. Kuang F, Ren J, Zhong Q, Liyuan F, Huan Y, Chen Z. The value of apparent diffusion coefficient in the assessment of cervical cancer. Eur Radiol 2013;23:1050-8. [CrossRef]

16. Zhang Y, Liang BL, Gao L, Ye RX, Shen J, Zhong JL. Diffusion weighted imaging features of normal uterine cervix and cervical carcinoma. $A i$ Zheng 2007;26:508-12.

17. Makino H, Kato H, Furui T, Morishige KI, Kanematsu M. Predictive value of diffusion-weighted magnetic resonance imaging during chemoradiotherapy for uterine cervical cancer. J Obstet Gynaecol Res 2014;40:1098-104. [CrossRef]

18. Kilickesmez O, Bayramoglu S, Inci E, Cimilli T, Kayhan A. Quantitative diffusion weighted magnetic resonance imaging of normal and diseased uterine zones. Acta Radiol 2009;50:340-7. [CrossRef]

19. Liu Y, Bai R, Sun H, Liu H, Wang D. Diffusion-weighted magnetic resonance imaging of uterine cervical cancer. J Comput Assist Tomogr 2009;33:858-62. [CrossRef]

20. Nakamura K, Joja I, Nagasaka T, Fukushima C, Kusumoto T, Seki N, et al. The mean apparent diffusion coefficient value (ADC mean) on primary cervical cancer is a predictive marker for disease recurrence. Gynecol Oncol 2012;127:478-83. [CrossRef] 